\title{
Editorial
}

\section{ADVANCES IN IMPLANT DENTISTRY}

\section{Ibtisam Al-Hashimi*}

\section{Salivary Dysfunction Clinic, Department of Periodontics, Baylor College of Dentistry, 3302 Gaston Avenue, Dallas TX 75246, USA}

Implant is becoming a mainstream practice in dentistry. Considerable advances have been made in this field with regard to applications, techniques, and materials used for dental implants.

This communication is intended to provide general practitioners, educators, and dental students with an overview of recent advances in implant dentistry. It covers a review of the history of implant in dentistry, approaches used for ridge preservation, ridge augmentation, guided bone regeneration, methods used for treatment peri-implantitis, and advances in implant dentistry for edentulous patients. Below is a brief description of the topics covered in this issue:

1. Historical Perspective on Dental Implant Coatings and Surface Treatment.

This manuscript provides a chronological history of dental implants, the physical, chemical, and biologic properties of dental implant coatings and mechanisms by which they augment the osseointegrative process.

2. Ridge Preservation for Implant Therapy: A Review of the Literature.

The requirement to have implants mimic the natural tooth in both function and esthetics makes the use of ridge preservation an essential element in the treatment planning for implant therapy. This review covers the healing dynamics of the extraction socket, the use of bone grafting materials and barrier membranes, and the evidence based literature supporting ridge preservation techniques.

3. Mechanism of Guided Bone Regeneration: A Review.

Crestal ridge bone resorption is an unavoidable consequence of tooth extraction, which often leads to a significant

*Address correspondence to this author at the Salivary Dysfunction Clinic, Department of Periodontics, Baylor College of Dentistry, 3302 Gaston Avenue, Dallas TX 75246, USA; E-mail: IAl-Hashimi@bcd.tamhsc.edu reduction in ridge dimensions. Guided bone regeneration is often required to provide adequate support for dental implant. Angiogenesis and ample blood supply plays a critical role in promoting bone regeneration. This article reviews techniques used to promote preservation of alveolar ridge dimensions.

4. Detoxification of Implant Surfaces Affected by PeriImplant Disease: An Overview of Non-Surgical Methods.

This article provides an overview of non-surgical approaches for detoxification of the surfaces of dental implant and treatment of peri-implant diseases.

5. The Evolution of Dental Materials for Hybrid Prosthesis.

This manuscript is a review of the progress in dental implant technologies and materials used for the treatment of edentulism.

The authors of this document are educators and practicing dentists; it is our hope that our colleagues and students find this document informative and useful.

\section{CONFLICT OF INTEREST}

The author confirms that this article content has no conflicts of interest.

\section{ACKNOWLEDGEMENTS}

The contribution of the reviewers was vital for the completion of this document; we would like to express our sincere appreciation and gratitude for the time and constructive comments of the reviewers. Namely, Salvador Nares, DDS, MS, PhD, Nancy Burkhart, PhD, Michael J Kowolik, BDS, $\mathrm{PhD}$, Steven B Blanchard, DDS, MS, Jose Mellado, DDS, DMD, MS, Larry Kudryk, DDS, Bruce Boretsky, DMD, Roger M Arce DDS, MS, PhD, Archie Jones DDS, MS, and Bhavani Venkatachalam DMD MS FACP.

(C) Ibtisam Al-Hashimi; Licensee Bentham Open.

This is an open access article licensed under the terms of the Creative Commons Attribution Non-Commercial License (http://creativecommons.org/licenses/by-nc/3.0/) which permits unrestricted, non-commercial use, distribution and reproduction in any medium, provided the work is properly cited. 